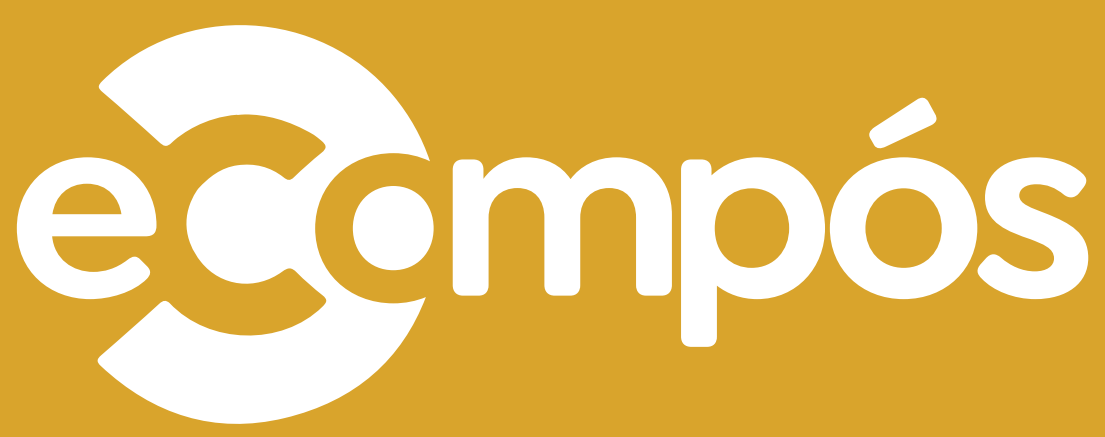

Revista da Associação Nacional dos Programas de Pós-Graduação em Comunicação

ISSN 1808-2599, v. 24, jan-dez, publicação contínua, 2021, p. 1-19.

doi.org/10.30962/ec.2263

\title{
Escutas de um ouvido autômato Estética e erotismo do ASMR
}

\section{FELIPE GUE MARTINI}

Centro Universitário da Serra Gaúcha (FSG), Caxias do Sul, Rio Grande do Sul, Brasil 


\section{/ resumo}

A partir de breve análise de dois vídeos ASMR - Autonomous Sensory Meridian Response (Resposta Meridional Sensorial Autônoma), disponiveis na rede social YouTube, o autor propõe um ensaio a respeito da escuta contemporânea. A subcultura do ASMR e a estética do formigamento são apresentados como modos emergentes de consumo audiovisual em diálogo com as noções de anestética, de Walter Benjamin, e de erotismo, de George Bataille. A hipótese decorrente é o surgimento de uma realização erótica e estética autômata, fruto da relação humana nas redes sociotécnicas, que potencializa a alienação do sono pelo capitalismo tardio.

Palavras-chave: ASMR. Anestética. Erotismo. Sound Studies.

\section{Escuchas de un oído autómata: estética y erotismo de el ASMR}

Desde un breve análisis de dos videos ASMR (Autonomous Sensory Meridian Response), disponibles en la red social YouTube, el autor propone un ensayo sobre la escucha contemporánea. La subcultura ASMR y la estética del hormigueo se presentan como modos emergentes de consumo audiovisual en diálogo con las nociones de anestésica, de Walter Benjamin y de erotismo, de George Bataille. La hipótesis resultante es la aparición de una realización erótica y estética automática, el resultado de la relación humana en las redes sociotécnicas, que agranda la alienación del sueño por el capitalismo tardío.

Keywords: ASMR. Anestética. Erotismo. Sound Studies.

\section{Listening an automaton ear: aesthetics and eroticism of ASMR}

From a brief analysis of two ASMR videos (Autonomous Sensory Meridian Response), available on the social network YouTube, the author proposes an essay about contemporary listening. The ASMR subculture and the tingly aesthetics are presented as emerging modes of audiovisual consumption in dialogue with the notions of anesthetics by Walter Benjamin and eroticism by George Bataille. The resulting hypothesis is the emergence of an automatic erotic and aesthetic realization, result of the human relationship in sociotechnical networks, which enhances the alienation of sleep by the late capitalism.

Palabras clave: ASMR. Anesthetic. Eroticism. Sound Studies. 


\section{/autor}

\section{Felipe Gue MARTINI}

Doutor e Mestre pelo Programa de Pós-Graduação em Comunicação da Universidade do Vale do Rio dos Sinos.

Coordenador do bacharelado em Jornalismo e do Tecnólogo em Cinema, do Centro Universitário da Serra Gaúcha FSG, Caxias do Sul, Rio Grande do Sul.

Centro Universitário da Serra Gaúcha FSG, Caxias do Sul, Rio Grande do Sul, Brasil.

E-mail: guemartini@gmail.com

\section{ORCID}

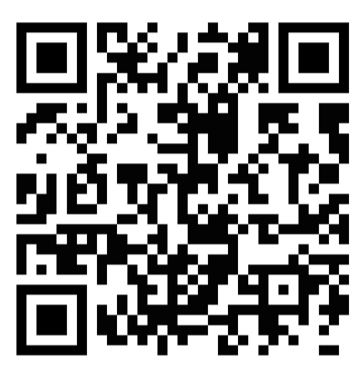




\section{Introdução}

Este ensaio apresenta uma abordagem teórica preliminar realizada através da observação exploratória de dois vídeos ASMR disponíveis no YouTube, escolhidos entre os mais populares do tema, a partir da questão: como a "estética do formigamento" e os vídeos ASMR podem ser interpretados à luz das teorias da escuta? O método proposto dialoga com a noção de escutas poéticas musicais, perspectiva que desenvolvi em minha tese, marcada aqui por uma relação entre a experiência estética de escutar os vídeos e as leituras teóricas derivadas ao escutar-se escutando. Abertura fenomenológica descrita em formato de ensaio científico.

\section{Shhhh... escuta!}

Um padeiro foi assassinado por seu vizinho que estava incomodado pelo barulho das máquinas da padaria. Um policial militar matou um jovem que brincava no telhado de uma clínica de saúde, indignado pela algazarra que o garoto fazia. Homem matou um casal de vizinhos do apartamento de cima e depois se suicidou - o motivo do crime era o incômodo provocado pelo filho do casal, de um ano e meio, que sobreviveu'. Notícias "comuns" sobre a potência sensorial e a violência presentes em torno da convivência humana com o sonoro.

Diante da ilusória individualidade, alta performance do capitalismo, o som é fonte de sociabilidade inevitável. Seu estado fluído e etéreo dificulta o isolamento. 0 som do outro é invasivo. Conforme vivemos e experimentamos os sons no espaço, criamos universos sonoros afetivos; a gestão de certo campo acústico pessoal é um modo de ser, é produção de identidade. 0 acúmulo dessa experiência fabrica nossa percepção auditiva, repertório individual que diferencia sons afetivos de sons banais. Boa parte das brigas e disputas sociais em relação ao espaço acústico vivido deriva dessas diferenças de percepção, um som bom para você, nem sempre é um som bom para mim (LE BRETON, p.109-126).

O mundo contemporâneo solicita nossa escuta de forma contundente e radical (OBICl, 2008). Não só através da poluição sonora de vizinhos ou desconhecidos, que abusam da potência estrondosa dos mini sound systems, mas nas publicidades escandalosas dos centros das cidades, nos alarmes que irrompem em madrugadas silenciosas, nos motores das indústrias, nos drones, nos zunidos infra e ultrassônicos das antenas, satélites, etc. Sobretudo nas grandes cidades, boa parte da disputa pela atenção se dá em campo acústico. A Era das Audibilidades (STERNE, 2003) parece atingir um estágio de excesso sensível nunca experimentado.

O desenvolvimento dos aparelhos sonoros marca uma fase importante do processo de produção social da escuta, tornada objeto de contemplação a ser medida, objetificada, isolada e simulada tecnicamente. Em meio a segunda revolução industrial, as técnicas de audição são transformadas gradualmente em comodities, produtos de compra e venda (STERNE, 2003, p.3) e os meios de comunicação elétrico e eletrônico, o telégrafo e o telefone, aparecem como as primeiras sistematizações de alto impacto social de uso do ouvido à serviço da técnica. Antes deles, no entanto, o estetoscópio mostrava um caminho de simbiose possivel entre homem-técnica-tecnologia. A manipulação concreta das escutas acontece a partir do domínio da gravação e da reprodução sonora (transdução), mas a suposta invenção dos aparelhos não é suficiente para estabelecer modelos de usos e consumos. Foi preciso produzir espiritualmente a escuta humana como ato, como modo socialmente aceitável de domesticação dos sentidos.

1 Disponivel em: <https://www.youtube.com/watch?v=2PH6Kpb8-w8>; <https://recordtv.r7.com/balanco-geral/videos/dono-de-padaria-e-mortopor-vizinho-por-causa-de-barulho-de-equipamentos-29102019>; <https://www.youtube.com/watch?v=nSCcFLRZaNo>. Acesso em: 12 fev. 2020. 
O debate sobre a fidelidade da reprodução sonora é um bom exemplo do percurso histórico e da plasticidade que a escuta e o discurso sobre ela adquirem ao longo do século XX. Essa espécie de busca pelo áudio elétrico-eletrônico-digital, que imitaria o som em seu contexto acústico, logo se transforma no modelo inverso, com os músicos tocando e cantando para os aparelhos, de acordo com eles, para depois, ao vivo, tentar imitar as gravações. As lógicas de alta fidelidade e baixa fidelidade ( $h i$-fi e lo-fi) aparecem como operadores discursivos da escuta, como modelos a serem conquistados através da alta tecnologia. Paralelo a esse movimento, sucatas, gambiarras, resíduos e apropriações sempre dão a ouvir outras dialéticas da evolução do mundo das sonoridades: música x ruído. Acreditarmos no potencial curativo do ASMR atravessa a noção de fidelidade, pois nossa escuta é plástica.

A plasticidade da escuta é audivel nos discursos sobre música e ruído. 0 auge da modernidade epistemológica (GUMBRECHT, 2010) apresenta a música tonal como uma espécie de física harmônica dos ouvidos, um paradigma de totalização do sensivel e do sublime kantiano, que logo dá lugar, no choque das vanguardas e da guerra, ao experimentalismo do dodecafonismo, do atonalismo, da música concreta e da música eletroacústica. Pierre Schaeffer (apud CHION, 1999) vai afirmar que é possível recortar qualquer som e nomeá-lo musicalmente - os futuristas imitarão a guerra como música, a música eletrônica vai surgir implodindo as noções modernas de timbre.

É claro que esse conto linear obscurece toda tradição popular, pagã, subterrânea dos usos sonoros rituais. Das entoações às palavras mágicas, dos pontos aos ritmos possessivos e frenesis de todas as ordens. O som organizado no tempo, na produção de ritmo, fornece muito mais do que entretenimento ou disputa, é o modo humano de experimentar o mundo. Se por um lado, a violência das intensidades nos interpela e ataca, o silêncio total significa a morte (como mostra a experiência da câmara anecóica, de John Cage)². 0 ruído implica e significa vida, no estetoscópio ou na pulsação. A existência é sônica, mesmo para quem não escuta - a própria visualidade é sinestésica, pois fornece noções sonoras, assim como o cinema mudo, que fala através daquilo que suscita visualmente do sonoro (CHION, 1999). Enquanto o ruído pode ser conduzido para alguma fonte, o silêncio é um fechamento para o interior, é tranquilidade e medo que, para fazer contato, precisa romper-se (LE BRETON, p.132-133).

A cotidianidade existe como uma espécie de musicalidade em fluência. É assim que Lefebvre interpreta a geografia, na sua dimensão rítmica histórica, que fornece o caráter de progresso à alienação moderna. O ritmo cotidiano como álibi do capitalismo, um fabricando o outro. Através da figura do torniquete, Lefebvre (1991) nos faz pensar que quando o capitalismo aperta demais, estanca a cotidianidade, como se matasse à míngua toda possibilidade de fruir a existência. Em tempos de aceleração turbocapitalista conforme Crary (2014) - e compressão espaço-temporal, a ilusão do cotidiano parece estilhaçada. Em larga medida pelos excessos. Essa sonoridade em despesa, que sobra, se volta contra si, produz descompassos entre o fluir cotidiano e a fratura da fantasmagoria (cisão entre obra e trabalho). 0 incômodo sensorial com os sons do outro é álibi para o assassinato. Surtar é uma expressão coloquial.

Nesse ambiente de abusos sensoriais (o mundo do trabalho e o mundo da vida se requisitando e atravessando um ao outro) encontrar descanso, relaxamento, reduzir as rotações se torna um desafio. Não se trata simplesmente de silêncio, mas de apaziguar a experiência de abundância. Abundância material. A velocidade das ofertas, da obsolescência dos produtos, da novidade e da cisão entre valor de troca e valor de uso é exponencial na sociedade do compartilhamento e da conexão. A participação é obrigatória para uma simbiose homem-máquina adequada, "no que você está pensando?", o Facebook interpela. Numa sociedade refundada e aglutinada em bolhas algorítmicas, o foco está na economia da atenção (BENTES, 2018). Até mesmo quando o voyerismo existe, numa observação silenciosa e tópica do ninja a flanar, a

2 Instalação que tinha um isolamento acústico total e revelou que, nesse suposto local de silêncio, os movimentos internos do nosso corpo tornam-se sonoros (WISNIK, 1989, p.19). 
ativação sensorial da escuta implica a transformação do ouvinte num medium da experiência (TOOP, 2016), os ouvidos não descansam num ponto fixo; como os olhos, eles são a espacialidade, buscam, ecoam, interpelam, atentam.

O som é uma ausência presente, o silêncio é um presente ausente. Ou talvez o inverso seja melhor: o som é uma presença ausente, o silêncio é uma ausência presente. Neste sentido, o som é uma ressonância sinistra - uma relação com o irracional e o inexplicável que desejamos e temos ao mesmo tempo. Quem escuta é, então, uma espécie de médium, alguém que percebe e se conecta com aquele que subjaz as formas do mundo ${ }^{3}$ (TOOP, 2016, p.12, tradução nossa).

O que estamos escutando? Pergunta retórica que pode dobrar-se sobre si mesma: o que escutamos quando escutamos? O que escutam nossos ouvidos? É a indagação de Jean Luc-Nancy (2003) quando reivindica essa espécie de fenomenologia privada e subjetiva dos sentidos. Escutar-se escutar como metáfora da própria fisiologia do ouvido (a trompa e o tímpano), ressoar, sentire (em italiano: escutar e sentir). Para Obici (2008), uma espécie de clínica acústica, que não trata apenas do silêncio (fóbico e estrondoso) das paisagens sonoras idílicas de alta definição de Murray Schafer ${ }^{4}$, mas que ultrapassa as dialéticas de som $x$ ruído e som $x$ música, no sentido de uma experimentação eclética, múltipla, sem paradigmas. 0 ruído constitutivo da diferença, dos tempos críticos, de quebra da própria banalidade do ouvido colonizado.

\section{Dois vídeos ASMR}

O ponto de partida deste ensaio são os vídeos ASMR - Autonomous Sensory Meridian Response (Resposta Meridional Sensorial Autônoma), uma modalidade emergente de produto audiovisual que circula em redes sociais da internet, formando uma subcultura de comunidades usuárias. Os ASMR privilegiam a captação do som e, geralmente, são gravados com microfones binaurais (permitem realizar captação estéreo para simular a escuta espacial dos dois ouvidos), a fim de reproduzir com muita proximidade sonoridades que provocariam, de forma autônoma, uma excitação física. Não proponho análise aprofundada em relação aos produtos, mas algumas reflexões e escutas decorrentes de minha experiência pessoal com eles.

Em texto de 2016, Rob Gallagher propõe uma análise estética do que chama de uma nova cultura de vídeo através das dinâmicas entre humanos e algoritmos no contexto dos artistas de ASMR. Como os sonoplastas da era de ouro da rádio ou algum apreciador das experiências de Pierre Schaeffer, os produtores têm como foco principal a manipulação sonora. No entanto, diferentemente dos períodos anteriores, que tinham fins artísticos e/ou científicos, agora à serviço de uma "estética do formigamento". Ao analisar o site Reedit, Gallagher (2016) mostra como as páginas iniciais dedicadas ao tema são avaliadas e ranqueadas a partir da quantidade e qualidade de formigamentos que provocam entre os usuários. O conteúdo dos vídeos ou as estratégias para fabricar os sons importam menos do que as sensações corporais que provocam. Os parâmetros para aceitação e popularidade obedecem à uma lógica de corporalidade, expressa através da infraestrutura comunicacional da rede, nas palavras do autor:

3 No original: El sonido es una ausencia presente, el silencio es un presente ausente. $O$ tal vez sea mejor su reverso: ?es el sonido una presencia ausente, es el silencio una ausencia presente? En este sentido, el sonido es una resonancia siniestra - una relacion con lo irracional y lo inexplicable que deseamos y tenemos al mismo tiempo. Quien escucha es, entonces, una especie de médium, alguien que percibe y se conecta con aquello que subyace a las formas del mundo.

40 pesquisador R. Murray Schafer faz uso da distinção de alta e baixa definição ao analisar as paisagens sonoras rurais e urbanas: segundo o autor o hi-fi (alta definição) possui uma razão sinal/ruído favorável, permite clareza, perspectiva (diferenciação figura/fundo), além de maior alcance auditivo, enquanto no lo-fi (baixa definição) "os sinais acústicos individuais são obscurecidos em uma população de sons superdensa" (SCHAFER, 2001, p.71-72), há uma ampla faixa de ruído e perde-se a perspectiva ótica; para o autor, a urbanização e as revoluções industrial e elétrica são ambientes favoráveis ao aparecimento e a hegemonia de paisagens sonoras lo-fi. 
a maneira pela qual a Internet está trazendo corpos e máquinas, agentes humanos e não humanos para novos tipos de correspondência, fomentando modos de engajamento com obras culturais que tratam mais de cibernética do que de hermenêutica: os vídeos r/asmr se tornam 'inputs' julgados não como mensagens a serem entendidas ou interpretadas, mas por sua capacidade de provocar 'outputs' afetivos e somáticos específicos. Essa capacidade é medida por meio de mecanismos de feedback (comentários, visualizações, "curtidas", votos positivos) que vinculam o público a usuários que enviaram e ao ASMRtist ${ }^{5}$ (GALLAGHER, 2016, n.p., tradução nossa).

Os gatilhos sensoriais favoritos do público, segundo pesquisa da universidade de Swansea (CANALTECH, 2019) são as sonoridades de Sussurros (75\%), Atenção pessoal (69\%), Sons nítidos (bater as unhas em objetos, arranhar, etc.) (64\%), Sons vagarosos (53\%), Sons repetitivos (36\%), Sorriso (13\%), Barulho de avião (3\%), Barulho de aspirador de pó (2\%) e Risada (2\%). Os efeitos somáticos desejados pelos usuários possuem um caráter terapêutico. Os formigamentos ajudariam no relaxamento corporal e na realização de um sono mais tranquilo. Ou seja, o significado ou a interpretação literal desses vídeos, dentro dessa comunidade, pouco importam. Gallagher (2016) ressalta que essa estética cibernética surge num período de precarização do capitalismo tardio, quando a humanidade se depara com as despesas e excessos de um sistema saturado pelo trabalho e pela irritabilidade sensorial. Os ASMR parecem apontar para uma resposta sensivel dentro do próprio sistema, um entorpecente capaz de desconectar conectando.

Como base para esse texto, assisti a dois vídeos de ASMR, escolhidos através de busca simples na rede social YouTube, a partir das palavras ASMR Brasil. Entre os vídeos mais assistidos e com produtores mais populares, escolhi dois, um de autoria de Sweet Carol: ASMR - Favo de Mel (eating sounds) ${ }^{6}$ e um segundo ASMR - Limpando seus ouvidos!?, de Bella Sant.

Os vídeos possuem aspectos similares. Em Favo de Mel (categoria eating sounds - sons de mastigação) a câmera fixa enquadra a autora (que usa fones de ouvidos) em primeiro plano, da boca até o peito, deixando fora de quadro a parte superior de seu rosto; no canto esquerdo da tela aparece o bojo de um microfone e em uma mesa onde Sweet Carol está debruçada, o pote plástico com um favo de mel (Figura 1). Ao longo de 11 minutos e 27 segundos, ela saboreia esse favo em frente à câmera estática e sussurra detalhes de seus atos e de suas preferências alimentares (interpelando o público). Seus únicos movimentos são em relação ao pote e ao favo, além de ir e vir até o microfone para enfatizar sons produzidos, seja por sussurros, seja pela mastigação ou manuseio do favo e do pote.

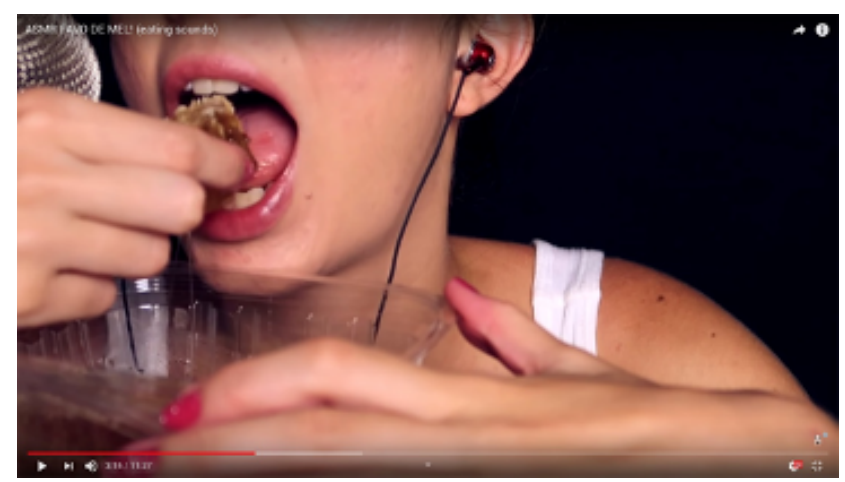

Figura 01: ASMR - Favo de mel! (eating sounds)

Fonte: Carol (2019)

5 No original: "there is the way that the Internet is bringing bodies and machines, human and nonhuman agents into new kinds of correspondence, fostering modes of engaging with cultural works that are more about cybernetics than hermeneutics: on r/asmr videos become "inputs" judged not as messages to be understood or interpreted but by their ability to elicit particular affective and somatic "outputs." This ability is measured via feedback mechanisms (comments, views, "likes," upvotes) linking audiences to uploaders and ASMRtist."

6 Disponivel em: <https://www.youtube.com/watch?v=rj7eLHIT4PE>. Acesso em: 07 jan. 2020.

7 Disponivel em: <https://www.youtube.com/watch?v=-Yr1ELEHIJA>. Acesso em: 07 jan. 2020. 
A estrutura de Limpando seus ouvidos é quase a mesma, no entanto Bella Sant revela todo seu rosto no primeiro plano, cortado entre testa e dorso. 0 microfone aparece quase inteiro centralizado na tela até sair de foco, em frente à boca da autora. Ao longo do vídeo, Bella Sant vai interagir com o microfone como se ele fosse o ouvido do usuário, realizando um processo de limpeza, explicado em detalhes através da voz sussurrada por 11 minutos e 20 segundos (Figura 2).

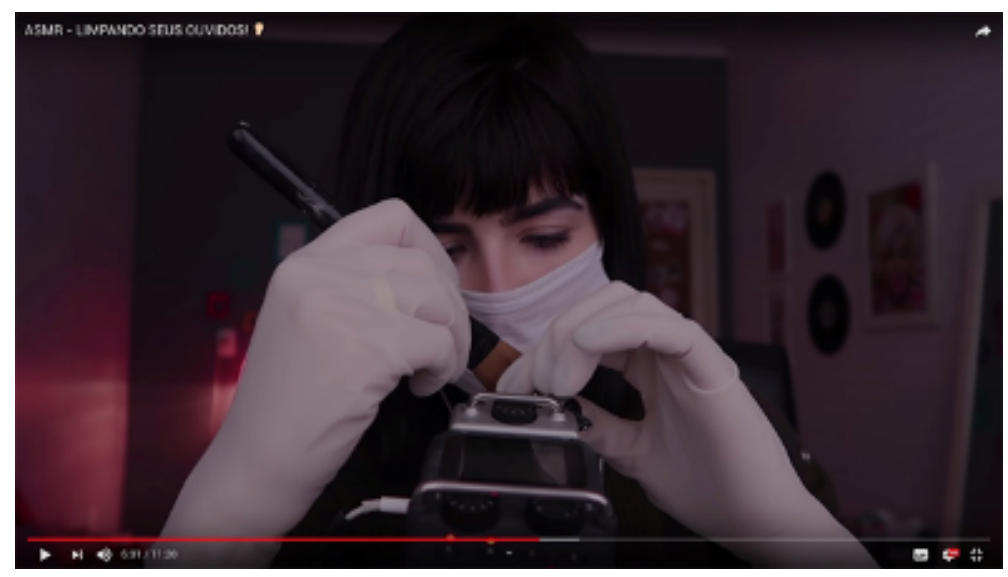

Figura 02: ASMR - Limpando seus ouvidos!

Fonte: Elaborado pelos autores (2020)

Ao destacar esses vídeos, não desconsidero seu caráter de consumo compartilhado. Para entender lógicas e sensibilidades em torno dos usos sociais, levo em conta contextos em que emergem, a rede informacional e a plataforma de vídeos YouTube, as práticas do mais do mesmo que caracterizam esses espaços (GALLAGHER, 2016), bem como a noção de comunidade ASMR, que tem como premissa e objetivo essa espécie de clínica sensorial audiovisual. Apesar disso, ao sentar em frente a tela, colocar os fones de ouvido e dar o play, não consigo evitar o estranhamento.

Embora não seja um fenômeno tão recente, os estudos científicos ainda não comprovaram os efeitos neurológicos do ASMR. Há indicativos psicofisiológicos levantados a partir de pesquisas quantiqualitativas com públicos que descreveram sensações e melhorias na qualidade do sono, nos sintomas de depressão e estresse (BARRAT; DAVIS, 2015). Mesmo sem comprovação científica atestada, a popularidade dos vídeos gera lucros para seus realizadores através dos acessos e de outras estratégias de monetização, como a liberação de conteúdos exclusivos ou parcerias com grandes marcas, tais como Ikea (dos EUA), Dove Chocolate e KFC. Existe um livro afirmando os benefícios do ASMR, escrito pelo criador de conteúdo Ben Nicholls (ASMR Gamer) intitulado ASMR: The Sleep Revolution (ASMR: A Revolução do Sono). A revolução narrada nas páginas afirma que essa subcultura pequena e emergente é fiel e que o ASMR é o gênero de relaxamento on-line que mais cresce no mundo (FOWLER, 2018, n.p.).

Empolgado pela propaganda, experimento os vídeos em meio à madrugada silenciosa de uma cidade de médio porte, munido de fones de ouvido, bem acomodado em minha cadeira. Não consegui muitos formigamentos. Um ouvido racional demais, talvez, não seja o instrumento ideal para esse desfrute. Além disso, sigo de forma precária as regras de utilização dos vídeos, principalmente Limpando seus ouvidos. Nesse vídeo, as instruções são claras, Bella Sant sugere que fechemos os olhos, que esqueçamos a visão a fim de entrarmos no estado de relaxamento. Sugestões numa entonação infantil: "Você pode deitar aqui na maca, não precisa ficar nervoso, é algo bem tranquilo, eu já passei por isso e senti muito relaxamento, talvez você até durma nesse processo" (SANT, 2018). De forma análoga, Sweet Carol cochicha exaustivamente seu 
fanatismo por favo de mel, acentuando sons guturais, estalos, chiados e sibilos. Talvez, essa experiência em laboratório esteja muito distante do uso cotidiano de quem sofre de insônia e ansiedade, mas foi minha aproximação do material empírico para fins de estudo.

\section{0 som das reticências}

Um primeiro aspecto que chama atenção é a ênfase visual na feitura dos sons. Essa dimensão de exibição, que à primeira vista parece uma sobra, já que o vídeo é feito para ser ouvido, se sobressai na minha experiência. Em geral, uma exibição do corpo feminino (no ASMR Brasil boa parte dos vídeos mais populares são de mulheres maquiadas e com certo padrão de beleza "majoritário", brancas, cabelos lisos, magras) ${ }^{8}$ em sua carga expressiva, no caso de Sweet Carol a boca que mastiga e fala, os dedos e as unhas que manipulam o pote e o favo, já Bella Sant com foco em seu olhar, pois a boca está escondida pela máscara, além de suas mãos que efetuam o processo medicinal no gravador. Sem ir a fundo nas imagens, é necessário apontar que elas estabelecem relações com o sonoro, ou seguindo os princípios de Chion (1999), conformando a própria cognição do audivel. Assim como na análise que Codato (2016, p.113) faz do filme Her, quando fechamos os olhos para relaxar, o corpo ausente é idealmente reconstituído "por meio da imagem/ da lembrança do corpo (e do rosto)" - no caso de Her, a atriz Scarlet Johansson, nos ASMR, as autoras.

$\mathrm{Na}$ metáfora de Limpando seus ouvidos, o microfone se transforma em órgão do espectador e Bella Sant age clinicamente sobre as superfícies de plástico e espuma do aparelho. 0 resultado dos atritos produzidos no equipamento é transposto diretamente para nossos ouvidos como numa simulação. Quando levamos em conta as imagens, podemos imaginar que os sons de limpeza de nossa carne equivalem a esses ruídos plásticos, inorgânicos e duros. Mas, será que ao fechar os olhos, esse descompasso derivado da esquizofonia ${ }^{9}$ desaparece? Vale notar o desinteresse total dos produtores em relação às fontes emissoras, recriando lógicas de fidelidade sonora. Uma vez que o interesse reside nos efeitos, vale tudo. Até mesmo sugerir que o som da carne equivale ao som do plástico. Tal postura sugere uma popularização das teorias e preocupações da música concreta e da dimensão plástica da escuta, pois parece superar o naturalismo e o realismo sonoro, de saída. Não há problema ao abordar as sonoridades de modo criativo, intervir de modo sensivel, criar atmosferas sem levar em conta as fontes emissoras (como seria o som real de um ouvindo sendo limpo?).

Mas como esse processo ocorre? Aqui, apesar dessa suposta inutilidade do discurso, aparece o direcionamento da fruição. Mesmo que a economia da atenção enseje a fabricação de uma desatenção, de um desligamento oscilante entre discurso e textura da voz, as falas direcionam para modos de crer (escutar para crer). Acredito que esse microfone é minha orelha e limpo meu ouvido interno ao limpar as superfícies do captador, as espumas protetoras. Acredito, ainda, que ouvir mastigação, voz gutural, estalos, chiados, estampidos, produzem relaxamento, geram formigamento, atualizam meu sono.

A escuta nesse contexto tátil aparece como uma prática de sinestesia (substituição, atravessamento ou potencialização de um sentido através de outro, no caso, do tato através da audição). Se desprende de uma produção de sentido na direção da pura presença (GUMBRECHT, 2010). Inundação sensorial em que as sonoridades adquirem funcionalidade de puro efeito e perdem sua complexidade numa objetificação simplista e determinada. Mas há um resto aí.

8 Embora aborde o tema do erotismo em seguida, não aprofundarei nessa questão, mas é uma dimensão importante, visto que existe uma subcultura popular de ASMR pornográfico, em que as sonoridades estão ligadas aos aspectos sexuais do corpo, sem descartar as imagens vinculadas a esses sons do prazer, tais como: masturbação, massagens, lambidas, chupadas, umedecimentos, manipulações de objetos fálicos, etc. Um dos principais canais do mundo é de Bella Brookz. Disponivel em: <https://onlyfans.com/missbella>. Acesso em: 20 fev. 2020. 
Por conta da ênfase no sonoro, as imagens parecem resíduo. Como esse significado que sobra atua sobre a recepção desatenta e sonolenta? Quais estéticas vazam desse substrato acessório? Ao receptor desatento ou mal-informado, a manutenção do aspecto visual dos vídeos soa até ridícula, por exemplo: uma mulher manipulando de forma ruidosamente repetitiva uma caixa plástica e a seguir mastigando (com a boca aberta para fazer ecoar os sons guturais) um favo de mel, enquanto sussurra suas preferências de apetite para a câmera, ou ainda uma outra mulher de guarda pó e máscara clinicando um gravador e interpelando o espectador de modo infantil. Fora de contextos, esses vídeos soam estranhos. Em texto anterior, propus a noção de figura-fundo para abordar as práticas musicais caseiras lo-fi (baixa fidelidade), onde a musicalidade estaria a fundo de uma presença física (da casa ou do corpo) como textura e tessitura da experiência estética desses produtos. Ao abordar as musicalidades do quarto escuro com essa metáfora visual, propus que boa parte da fruição do lo-fi reside nessa vida de fundo, que vaza e se faz presente em processo oscilatório (ruídos do corpo, interferências de sinal, vazamentos, interrupções, latidos, carros, geladeiras, vozes, etc). Assim como as ilusões de óptica do efeito phi, o lo-fi fabricaria uma irritabilidade sensorial dinâmica, a dialética da música x ruído audivel, em si (MARTINI, 2018)10.

Como ler o ASMR a partir dessa lógica? O que esse corpo sussurrante em busca de fabricar calafrios desenvolve como modo de atuação, como performance, como estratégia discursiva (antidiscursiva), reinventando e reinserindo a presença como prática? Posso afirmar que nos vídeos ASMR, enquanto o áudio torna-se figura, a visualidade se esconde no fundo ou fabrica outras imagens espectrais, na imaginação do usuário?

É muito comum no lamento dos artistas de ASMR aquela espécie de apelo emocional ao ouvinte da rádio, fala interpelativa solicitando ação, participação e atenção. Lembram os locutores das madrugadas e suas estratégias vocais texturizadas (afirmar o timbre para seduzir o ouvinte). Ao mesmo tempo em que produzem um "carinho envolvente", são as texturas dos sons vocais (sibilos, chiados, salivações) que fabricam o desligamento, o relaxamento e a redução do estresse (além de outros ruídos produzidos pelas mãos, objetos e máquinas). As falas lembram estéticas da autoajuda, do empreendedorismo fácil, do coaching de fim de semana. Interessante pensar que assim como alguns cursos de inglês em fita cassete para estudar dormindo dos anos 1990, as mensagens parecem adentrar a área nebulosa semi-consciente dos usuários. Justamente a zona ainda livre do capital (CRARY, 2014) aparece aqui sob ameaça, graças a essa estética inovadora. Podemos imaginar que os anúncios presentes nos entretempos da programação normal sejam consumidos em modo soneca, mas as próprias falas, enquanto itens acessórios, podem fabular modelos mentais para recepção subconsciente. Não seria o ASMR a mais nova arma tática da conquista de nossa escuta em seu tempo mais frágil? Tudo cabe nesse enunciado que, afinal, habita ainda um segundo plano da sonoridade. Se reabríssemos a dinâmica figura-fundo uma vez mais, para abordar somente as sonoridades, aqui o sentido das falas estaria mais ao fundo, como cenário para o protagonismo dos ruídos da boca, mãos, máquinas e objetos captados em primeiro plano pelo gravador.

A emersão do fundo como valor acontece através de um procedimento tecnológico. Assim como a câmera lenta fornece ao cinema um olho cirúrgico (BENJAMIN, 2000), o uso estereofônico do microfone binaural aproxima ouvidos dos pormenores sonoros (SZENDY, 2015). A amplificação sensorial recria o campo auditivo, como se estivéssemos mais próximos (apesar da distância da mediação computacional) de nossos próprios sons corporais. O ASMR no YouTube funciona como estetoscópio digital à distância, assim como no início da música gravada passamos a ouvir e apreciar os sussurros dos crooners e as texturas vocais de baixa potência como escuta complementar aos vozeirões dos astros da música de câmara. Plasticidade da escuta.

10 Importante salientar que a visão defendida aqui em relação às distinções música e ruído ou som e ruído não é naturalista ou essencialista. Aproprio-me da visão de Wisnik (1989) quando afirma que essas relações são dinâmicas e dialéticas e que dependem dos contextos culturais e dos usos sociais das sonoridades em seus espaços-tempo históricos. 
Ao dispor da atenção desatenta aos sons corporais do outro à distância, simulamos uma auscultação mediata, como proposta por Laënnec ao criar o estetoscópio e melhorar os diagnósticos médicos, até então, realizados pelos métodos percussivos (batidas no corpo em busca de ressonâncias semiológicas): "al interponer un dispositivo técnico entre los cuerpos resonantes se puede empezar a escuchar al otro sin escucharse a sí mismo" (SZENDY, 2015, p.58). Diferente da ausculta diagnóstica, no entanto, aqui é o doutor quem está em busca de cura. Não escuto o outro para curá-lo, mas para curar-me. Ou, saindo da metáfora simplista, dou um salto na direção desse corpo tecnorgânico com o objetivo de deixar de escutar-me, apesar de simular a escuta de minhas sonoridades interiores. Mas será possivel cessar essa duplicidade da escuta de escutar-se ressoar (escutar-se escutar), sobretudo quando lidamos com dois duplos (o ouvido sobre si mesmo e os dois ouvidos na escuta estereofônica)?

$\mathrm{Na}$ impossibilidade do silêncio, seja do próprio corpo, seja do entorno, essa escuta, que ganha características de ausculta, traz ao primeiro plano níveis não-linguísticos das falas. Relativizado o interesse pelo sentido (apesar de sua presença indissociável da forma) auscultamos as borbulhas (o interesse de Läennec com o estetoscópio sobre o tórax e o abdome), uma espécie de ladainha asséptica, porque liberta da carga imperiosa do significado. Ao excesso de sentido, tal movimento sugere pura presença, indeterminável, capaz de conduzir ao relaxamento e alento momentâneos, soporíferos. Não é fala, nem silêncio, talvez aspas...

Sem dúvida, é necessário.

É necessário deter-se. E talvez aqui mais do que em qualquer outra parte é necessário deter-se nos pontos de suspensão antes das aspas que fecham.

Em inglês se denominam elipsis.

A elipsis na borbulha das aspas, onde se abre todo um mundo aprofundado de dentro ${ }^{11}$ (SZENDY, 2015, p.100, grifo do autor, tradução nossa).

"A elipse na borbulha das aspas" onde se abre todo um mundo aprofundado do interior. Uma má tradução, uma tradução imperfeita do que Szendy (2015) expressa como timpanização da filosofia (termo emprestado de Derrida). Lendo Nietszche, Derrida e Heidegger, sondando como a pontuação, a sobrepontuação, a percussividade e outras figuras do sonoro permeiam seus modos de razão, ele traça esse paralelo entre a objetificação da escuta na medicina, na filosofia e na guerra. Filosofar com o martelo, como afirma Nietszche em Crepúsculo dos Deuses.

Embora o ASMR exiba percussividade, para mim está nos sussurros e nos chiados seu potencial estético (ou anestético, veremos adiante). Portanto, recorre não ao estampido suspenso das aspas, mas a uma espécie de intermitência dos três pontos. 0 mais do mesmo sonoro, mas permeado do falatório ou da ação. O silêncio possivel na era da conversação (BENTES, 2018). Em certo sentido, ativa a imagem do prático-inerte, de Sartre, que nega o som de fogueira, floresta, mar, ruído branco, ao manter atividade, produzir capital através das visualizações, curtidas, reputações comunitárias, enquanto, simplesmente, é reprodução, vazio e tatilidade. Braile para os ouvidos. 


\section{Anestética para ouvidos moucos}

Ao escrever sobre o cinema, Benjamin (2000) afirma a experiência do choque e do potencial opressor da reprodução das imagens em movimento. A montagem cinematográfica, ao mesmo tempo em que permite um aprofundamento da percepção através da aproximação, das câmeras lentas, da manipulação do tempo, se oculta na experiência, se mascara e somente se desvenda através de um inconsciente óptico.

Com efeito, a sucessão de imagens interdita tôda associação no espírito do espectador. É disto que decorre sua influência traumatizante; como tudo o que choca, o filme não pode ser captado senão graças a um esfôrço mais intenso da atenção. Por sua técnica, o cinema liberou o efeito de choque físico da ganga moral em que o dadaísmo, de certo modo, o havia encerrado (BENJAMIN, 2000, p.234) ${ }^{12}$.

O inconsciente óptico é inspirado no inconsciente pulsional, de Freud. Uma vez que "o choque é essência mesma da experiência moderna", seria uma atuação da consciência que anestesia o sistema nervoso frente aos estímulos do exterior e isola o presente da memória de seu passado, por necessidade de sobrevivência, "não por entorpecimento, mas por inundação dos sentidos", um efeito neurológico. Debaixo da euforia participativa das salas do cinema e da arte como "realidade a ser exposta", Susan BuckMorss (1996) propõe que Benjamin mostrava através dessa noção o esforço por um controle total sobre as populações. Segundo a autora, além da afetação sensorial e da aculturação advindas da arte, a experiência estética traria consigo condições paralinguísticas e elementos não-civilizáveis. 0 desenho de abertura na rede neuronal levaria a uma indissociabilidade entre o mundo exterior e o circuito sensorial do cérebro.

O campo do circuito sensorial corresponde assim ao da 'experiência', no sentido filosófico clássico da mediação entre sujeito e objeto, e no entanto a sua própria composição torna a dita separação entre sujeito e objeto (e que era tormento constante da filosofia clássica) simplesmente irrelevante (BUCK-MORSS, 1996, p.19, grifo da autora).

A autora chama de sistema sinestético a fusão da experiência estética com a realidade do meio externo, "sistema estético de consciência sensorial, descentrado do sujeito clássico, no qual as percepções sensórias exteriores se enfeixam nas imagens internas de memória e de antecipação" (BUCK-MORSS, 1996, p.19). A descrição que Benjamin faz do cinema aparece como exemplo desse atravessamento, mas longe de representar uma redenção, já que, apesar de potente, preserva as características da sociedade de classes marcada pela dissociação entre obra e trabalho (fantasmagoria) e entre valor de troca e valor de uso (fetichismo). A suposta liberdade é marcada pela racionalidade capitalista que abre caminho para um fascismo populista na estetização da política. A expansão desses modos de fruição leva Buck-Morss a afirmar que não estaríamos mais diante de um sistema sinestético, mas anestético, que expulsa o mundo exterior por deflexão ao invés de manter ativas capacidades miméticas de assimilação e aprendizagem. O sistema se autonomiza, como nas fábricas, onde "a memória é substituída pela resposta condicionada" (BUCK-MORSS, 1996, p.23-29).

O choque físico do espaço fabril e das sucessivas guerras do século XIX, dá lugar, aos poucos, ao choque mental, interno, quando a anestética se torna método de entorpecimento coletivo (Buck-Morss cita o uso dos opiáceos, que saem das clínicas para as ruas), quando "o narcótico torna-se a própria realidade" (conforme Benjamin citado por Buck-Morss, 1996, p.28). A experiência de fratura da modernidade vai muito além do uso de drogas, que são apenas um sintoma dessa espécie de insensibilidade latente advinda da abundância de estímulos. 
Fantasmagorias são tecnoestéticas. As percepções que oferecem são 'reais' o quanto baste - o seu impacto sobre os sentidos e nervos é ainda 'natural' de um ponto de vista neurofísico. [...] Tem o efeito de anestesiar o organismo, não por entorpecimento, mas pela inundação dos sentidos (BUCK-MORSS, 1996, p.27, grifo da autora).

Elas alteram a consciência e, ao contrário das drogas, têm efeito coletivo ao invés de individual. São fato objetivo e norma social.

A fantasmagoria é tecnoestética pois os produtos, desvinculados do valor trabalho, tornamse onipresentes e excitam nosso sistema nervoso através de uma indistinção entre corpo e mercadoria, onde só é possivel viver anestesiado. Ao abordar esse potencial estético da obra de arte, Benjamin estaria evocando o mergulho sensorial como contra-tecnologia e escudo, a fim de

\footnotetext{
[...] desfazer a alienação do aparato sensorial do corpo, restaurar o poder instintual dos sentidos corporais humanos em nome da auto-preservação da humanidade, e isto, não através do rechaço às novas tecnologias, mas pela passagem por elas (BUCK-MORSS, 1996, p.12, grifo da autora).
}

A princípio, o uso clínico calmante de sonoridades não é novidade. Há algum tempo, temos disponíveis dentro do próprio YouTube vídeos com horas de sons de mar, chuva, cascata, fogueira e etc. Existem para venda na internet pacotes de ruído branco, seja para ninar crianças ou para amenizar sintomas de doenças auditivas. No meu feed do Instagram, anúncios de aplicativos sonoros anti-ansiedade são frequentes (será por conta de algum cálculo algorítmico em relação ao movimento de meus dedos e pupilas ou algo mais rudimentar, como um cruzamento simples de dados com base nas minhas buscas por ASMR?). Ao longo da história, as diferentes culturas utilizaram (e ainda utilizam) seus sons rituais, vinculados aos diferentes aspectos de suas vidas em sociedades. Sons para dormir, sons para acordar, sons para reverenciar, sons para guerrear, sons para marcar o tempo, etc. A teoria musical moderna é apenas uma etapa de racionalização radical, mas as práticas vernaculares persistem e resistem. Há uma disciplina chamada musicoterapia dedicada, também, a esses fenômenos. Talvez, a própria noção de arte ASMR seja mais uma efeméride da rede, sem relevância potencial.

No entanto, o aspecto sonoro do ASMR é importante pois aponta para o estabelecimento de uma rede de aprendizagens e relações erótico-estéticas no atravessamento do corpo pelas mídias. A estética do formigamento aparece como a assunção do transbordamento sensorial descrito por Buck-Morss. Como se não tivéssemos mais alternativa para lidar com o choque moderno do que atravessá-lo com mais entorpecimento. Essas táticas promovem desalienação ou apenas anestesiam ainda mais nossos corpos? São resistência ou sintoma social?

\section{Entre o erotismo e a anestética}

"Segredos de liquidificador" via rede, as falas e os corpos evocados no ASMR revelam um aspecto erótico, que abordo a partir de imagens suscitadas pela leitura de George Bataille. Para esse autor, o erotismo é uma diferenciação humana em relação à sexualidade animal. É uma experiência interior que busca e deseja o exterior. Sua força reside na descontinuidade do ser, pois todo homem está só, nasce e morre só, está dividido dos seus semelhantes por um abismo. 
O sentimento erótico é, ao mesmo tempo, um ímpeto na direção da morte e da fusão entre dois seres descontínuos, na tentativa de estabelecer continuidade. Ele não é diretamente ligado à reprodução, mas a atravessa, pois a reprodução sexual, no íntimo, no ser interior, é uma fusão e uma destruição (espermatozóide e óvulo). Dois que se fundem, acabam, morrem, para dar vida a um, "O novo ser é, ele mesmo descontínuo, mas traz em si a passagem à continuidade, a fusão, mortal para cada um deles, dos dois seres distintos" (BATAILLE, 1987, p.12).

Para Bataille, a vida é uma busca de passagens do descontínuo para o contínuo, graças à nostalgia cultivada pela continuidade perdida (a fecundação), motivada pelo desejo de superar o isolamento, até a morte, que expressa a continuidade (principalmente no aspecto religioso, em sua promessa de eternidade e apaziguamento do ímpeto nostálgico). Nesse sentido, todo erotismo é sagrado, ou seja, apresenta uma espécie de transcendência do abismo para a continuidade, embora também possamos viver experiências dos outros dois tipos: o erotismo dos corpos e o erotismo dos corações. O erotismo sagrado é o terceiro tipo e, em certo sentido anima os outros dois. O sagrado, aqui, ultrapassa o religioso (culto), pois trata da busca "para além do mundo imediato", como aspecto que transborda ao atravessar a animalidade do ser. Por isso, o erotismo sagrado vive nos outros dois, que estão mais ligados à materialidade, em si, do corpo: como continuidade através das carnes, das peles; e do coração: como a paixão e o desejo da fusão dos corpos entre si.

O erotismo dos corpos tem de qualquer maneira algo de pesado, de sinistro. Ele guarda a descontinuidade individual, e isto é sempre um pouco no sentido de um egoísmo cínico. 0 erotismo dos corações é mais livre. Ele se separa, na aparência, da materialidade do erotismo dos corpos, mas dele procede, não passando, com frequência, de um seu aspecto estabilizado pela afeição recíproca dos amantes. Ele pode se desligar inteiramente daquele, mas isto são exceções, justificadas pela grande diversidade dos seres humanos (BATAILLE, 1987, p.15).

Ao comentar a obra de Bataille, Jean-Luc Nancy (2013) afirma que a opção do escritor ao abordar o erotismo como experiência interior de ímpeto transcendente seria uma espécie de sintoma de época, frente ao esgotamento das "visões de mundo" da filosofia. O interior substitui a mística, e o sagrado se refere à relação do homem com os elementos intangiveis e inacessiveis pelas ordens da razão. A experiência interior não se insere na racionalidade ou no inconsciente, mas é uma espécie de conexão com a exterioridade:

[...] o fora se abre dentro, meu 'quanto a mim', minha individualidade, minha pessoa, tudo isso se revela pelo que é, envoltórios indispensáveis de uma vida que no fundo dela mesma se mistura a todas as outras e ao resto do mundo (NANCY, 2013, n.p.).

O interior de Bataille é composto pelas exterioridades, mas, diferente do sistema anestético, preserva um élan de vitalidade.

Em Benjamin, a fragmentação percebida pelos filósofos do início do século XX promove um empobrecimento da experiência. Esse estágio de crise dos modelos familiares, das tradições religiosas, do acréscimo de violência sensorial sugere um mundo exterior que fratura razão e sensibilidade. Anestesia coletivamente (do exterior para o interior, que ao final formam um sistema sensivel indistinto). A naturalização da cultura afirma a barbárie presente no progresso e a única vida possivel é anestética. Como parte desse entorpecimento, viver sob o capitalismo adquire um caráter cultual. No breve texto chamado Capitalismo como religião, essa sociedade é apresentada como religião sem teologia, "Nada nele tem significado que não esteja em relação imediata com o culto, ele não tem dogma específico nem teologia. 0 utilitarismo ganha, desse ponto de vista, sua coloração religiosa" (BENJAMIN, 1985 apud LOWY, 2005, n.p.).

O culto do capitalismo não dá trégua ou piedade, "não existem dias comuns!" Sua repetição reproduz o modelo e mantém a tensão do adorador, da mesma forma que a experiência interior, em Bataille (1997). A realização total do erótico é a continuidade, a morte, que para a religião implica numa nova vida, eterna. E na 
religião do capitalismo? Uma resposta possível, talvez, esteja na antecipação proposta por Baudelaire quando afirmou que "o homem é um animal adorador" e que "adorar é se sacrificar e se prostituir" (NANCY, 2005, n.p.). Na sociedade anestética, o impulso para o exterior do erotismo pode ser ainda mais dilatado. As reticências podem promover respostas motoras ao infinito, fabricando uma espécie de continuidade perene. 0 que seria possivel somente através do acesso ao sagrado via sacrifício, com a própria morte ou oferenda, torna-se persistente, passa a integrar a vida e o cotidiano. A realização erótica na rede sociotécnica é continuidade, uma espécie de morte física do descontínuo para um renascimento erótico sagrado tecnorgânico.

Um dos episódios mais marcantes da história da arte, a orelha cortada de Van Gogh é vista por Bataille como sacrifício erótico, "un impulso revelado por una experiencia interior" (2003 apud TOOP, 2016, p.239). A continuidade que resiste a essa adoração é transposta em arte, o autorretrato. A morte em sacrifício dá lugar à vida da criação, transpõe o abismo entre um e o outro, entre um e os outros, chega ao exterior atravessando a interioridade. A orelha aparece para Van Gogh como uma parte relativamente pouco importante em relação ao sacrifício que the possibilita liberdade. Qual o resultado de nossos sacrifícios cotidianos, ao entregarmos, todas as noites, nossas orelhas e ouvidos para a religião tecnoestética da rede computacional? Será que para nós, assim como para Van Gogh, a orelha vale tamanho sacrifício?

Quando dormimos aos sons de Limpando os ouvidos, com essa prótese "orelha gravador fone de ouvido" tentando, nós também, transpor o abismo da fibra óptica, descontinuidade acelerada e anestesiada pelo veludo do ciberespaço, estamos em sacrifício. Nosso culto à religião do capitalismo não precisa mais nem de nossa vigília, pois fabricamos mais valia, papel-moeda sem lastro, na adesão sonâmbula. Enquanto sussurros, grunhidos, sibilos embalam nossos sonhos num erotismo corporal (a estética do formigamento), o fundo sagrado que reside como potência, anestesiado pelo cansaço permanente do ritmo do progresso, flui para a reprodução do álibi. Nem dormindo, estamos livres de prestar reverência, de entregar em sacrifício corpo e espírito, na expectativa ilusória de paz.

O sacrifício é violência que pode romper na direção da liberdade. Mas estamos presos a um torniquete. Quanto mais emprestamos nossos ouvidos subconscientes para as lógicas da economia da atenção, mais nos aprisionamos ao libertar o capital que flui dessa audiência (audição). Nosso sono embalado pelas redes é o álibi da mais-valia do mais do mesmo. Até que ponto esse relaxamento produtivo, que gira a roda do sistema, não exibe a potencial violência do erotismo esvaziado? Experiência anestética $e$ anerótica. Somos o prático-inerte no culto religioso das máquinas.

Encalacrados pelo excesso, os ouvidos parecem estar em permanente estado de excitação. Vez ou outra se manifestam sintomas de violência física (como nos casos narrados na introdução) ou sensorial (surtos, paralisias, doenças neuronais). É comum, porém, brotarem mecanismos de fuga, negações, surdez anestética. Entorpecimento dos sentidos, inundação.

\section{0 ouvido autômato de um ser zumbi}

Um último aspecto em relação ao ASMR diz respeito à expectativa da resposta sensorial autônoma. Embora, ainda sem comprovação confiável, parece um pouco assustador imaginar que através do uso de sonoridades simples poderemos desencadear ações irrefletidas nos corpos ouvintes. Apesar do sono ser uma necessidade biológica, a ansiedade em torno de sua prática se manifesta como uma autoridade interna dos sujeitos. Precisamos dormir para estarmos prontos ao sistema produtivo, mas sem a necessidade de um Grande Irmão ou um toque de recolher que nos obrigue. Entre as possiveis respostas a esse sintoma social, Erich Fromm cita o conformismo de autômatos. 
Grande número de nossas decisões não são de fato nossas, mas nos são sugeridas de fora; conseguimos persuadir-nos de que somos nós que tomamos a decisão, quando na realidade nos conformamos com as expectativas dos outros, impelidos pelo temor ao isolamento e por ameaças mais diretas à nossa vida, liberdade e bem-estar (FROMM, 1986, p.161).

Queremos, de fato, dormir? O tratamento anestético da ansiedade sugere essa conformação, uma tentativa de desativar a razão confiando no estímulo-resposta do corpo. Uma vez comprovada a hipótese da estética do formigamento como modelo autônomo de controle sensorial, quais serão os próximos passos? Que outras respostas desejaremos para os corpos através de seus ouvidos?

Antes, porém, de encarar a cultura ASMR como arma sônica de manipulação de massas (num determinismo fútil e rasteiro), acho que é a impessoalidade do coletivo e dos rizomas indetermináveis dos usos e compartilhamentos que potencializam sua força. O poder difuso, mas atomizado, nutre a sensação ilusória de liberdade. A autonomização não é mais simbólica e cultural - conforme Hall (2003) -, mas passa a ser somática. Aqui, vale referir a provocação interessante de António Damásio (1994, p.191-204), em seu livro 0 erro de Descartes, quando apresenta, ainda nos anos 1990, a hipótese do marcador somático. As tomadas de decisão não passam, necessariamente pela razão, pelos procedimentos de ponderação e análise, mas fazem uso de um nível intuitivo, baseado em sentimentos gerados por emoções secundárias. Mesmo a racionalidade está atravessada pelo sensório. 0 que poderíamos fazer pensar se controlássemos essa entrada e saída de emoções e sensações? As respostas autônomas não tratam apenas de anestesiar os ritmos da vida, mas podem indicar um sutil controle da experiência erótica e estética nas suas relações com a política e com a tomada de decisões racionais. Afinal, não há razão humana sem corpo, erótico e estético. 


\section{Referências}

ASMR. O QUE É e porque esse tipo de vídeo viralizou na internet? Canaltech , 12 fev. 2019. Disponível em: <https://canaltech.com.br/virais/asmr-o-que-e-e-porque-esse-tipo-de-video-viralizou-nainternet-132625/>. Acesso em 06 fev. 2020.

BATAILLE, George. 0 erotismo. Porto Alegre: L\&PM Editores, 1987.

BARRATT, E.L.; DAVIS, N.J. Autonomous Sensory Meridian Response (ASMR): a flow-like mental state. PeerJ, 3, e851. 2015. Disponivel em:<DOI 10.7717/peerj.851>. Acesso em: 04 fev. 2020.

BENJAMIN, Walter. A obra de arte na época de sua reprodutibilidade técnica. In: LIMA, Luiz Costa. Teoria da Cultura de Massa. São Paulo: Paz e Terra, 2000. p. 207-239.

BENTES, Ivana. Economia narrativa: do midiativismo aos influenciadores digitais. In: BRAIGHI, Antônio Augusto; LESSA, Cláudio; CÂMARA, Marco Túlio (Orgs.). Interfaces do Midiativismo: do conceito à prática. Belo Horizonte: CEFET-MG, 2018. p. 151-169.

BUCK-MORSS, Susan. Estética e anestética: O "Ensaio sobre a obra de arte" de Walter Benjamin reconsiderado. Travessia, Florianópolis, n.33, ago./dez. 1996, p. 11-41.

CAROL, Sweet. ASMR FAVO DE MEL! (eating sounds). 3, fev. 2019. YOUTUBE: Sweet Carol. 1Disponível em: <https://www.youtube.com/watch?v=rj7eLHIT4PE\&t=195s>. Acesso em: 10 jan. 2020.

CHALON, Madeline; NANCY, Jean-Luc. Entrevista com Jean-Luc Nancy. Mas deixemos de lado o senhor Bataille. Alea: Estudos Neolatinos. v.15, n.2. Rio de Janeiro, jul./dez. 2013. Disponível em: <https://doi. org/10.1590/S1517-106X2013000200012>. Acesso em: 08 jan. 2020.

CHION, Michel. El sonido. Música, cine, literatura... Barcelona: Editorial Paidós, 1999.

CODATO, Henrique. O corpo e a Voz no Cinema Contemporâneo: reflexões sobre o filme Ela (Her, 2013), de Spike Jonze. Significação. v.43. n.46. 2016. p.106-125.

CRARY, Jonathan. 24/7: Capitalismo tardio e os fins do sono. São Paulo: Cosac Naify, 2014.

DAMÁSIO, António. 0 erro de Descartes. Emoção, razão e o cérebro humano. São Paulo: Companhia das Letras, 1994.

FOWLER, Damian. O que é ASMR - os intrigantes sons que valem ouro no youtube. BBC Brasil, 5 ago. 2018. Disponivel em: <https://www.bbc.com/portuguese/vert-cap-44829944>. Acesso em: 14 jan. 2020.

FROMM, Erich. 0 medo à liberdade. 14. ed. Rio de Janeiro: Guanabara, 1986.

GALLAGHER, Rob. Eliciting Euphoria Online: The Aesthetics of "ASMR" Video Culture. Film Criticism. v. 40, ed. 2., jun. 2016. Disponivel em: <http://dx.doi.org/10.3998/fc.13761232.0040.202>. Acesso em: 10 jan. 2020. 
GUMBRECHT, Hans Ulrich. Produção de Presença. 0 que o sentido não consegue transmitir. Rio de Janeiro: Contraponto/Ed. PUC-Rio, 2010.

HALL, Stuart. Da diáspora: Identidades e Mediações Culturais. Belo Horizonte: Editora UFMG, 2003.

HARVEY, David. Condição pós-moderna. 25 ed. São Paulo: Loyola, 2014.

LE BRETON, David. Il sapore del mondo. Un'antropologia dei sensi. Milão: Raffaello Cortina Editore, 2007.

LEFEBVRE, Henri. A vida cotidiana no mundo moderno. v. 24. São Paulo: Ática, 1991.

LÖWY, Michael. O capitalismo como religião. Folha de São Paulo, 18 dez. 2005. Disponível em: <https:// www1.folha.uol.com.br/fsp/mais/fs1809200508.htm>. Acesso em: 07 fev. 2020.

MARTINI, Felipe Gue. Platina: transmetodologia radical e escutas poéticas entre Porto Alegre e Montevidéu. 2018. 261 f. Tese (Doutorado em Ciências da Comunicação) - Unisinos, São Leopoldo, 2018.

NANCY, Jean-Luc. A la escucha. Buenos Aires: Amorrortu, 2007.

Ascoltando. In: SZENDY, Peter. Escucha. Una história del oído melómano. Barcelona: Ediciones Paidós Ibérica, 2003. p.11-16.

OBICl, Giuliano. Condição da escuta. Mídias e territórios sonoros. Rio de Janeiro: 7Letras, 2008.

SANT, Bella ASMR. ASMR - LIMPANDO SEUS OUVIDOS! 03, nov. 2018. Youtube: Bella Sant ASMR. Disponível em: <https://www.youtube.com/watch?v=-Yr1ElEHIJA>. Acesso em: 11 jan. 2020.

SARTRE, Jean-Paul. Questão de método. Trad. Bento Prado Júnior. São Paulo: Abril Cultural, 1973.

SCHAFER, R. Murray. A afinação do mundo. São Paulo: Unesp, 2001.

STERNE, Jonathan. The Audible Past. Cultural Origins of Sound Reproduction. Durhan and London: Duke University Press, 2003.

SZENDY, Peter. Escucha. Una história del oído melómano. Barcelona: Ediciones Paidós Ibérica, 2003.

TOOP, David. Resonancia siniestra. El oyente como médium. Buenos Aires: Caja Negra, 2016.

WISNIK, José Miguel. 0 som e o sentido. 2. ed. São Paulo: Companhia das Letras, 1989. 


\section{Informações sobre 0 artigo}

Resultado de projeto de pesquisa, de dissertação, tese

Não se aplica.

Fontes de financiamento

Bolsa CAPES.

\section{Considerações éticas}

Não se aplica.

Declaração de conflito de interesses

Não se aplica.

\section{Apresentação anterior}

Não se aplica.

\section{Agradecimentos/Contribuições adicionais}

NIPP - Núcleo de Inovação em Práticas Pedagógicas, da FSG -

Centro Universitário da Serra Gaúcha. Adriana Antunes Poletto. 